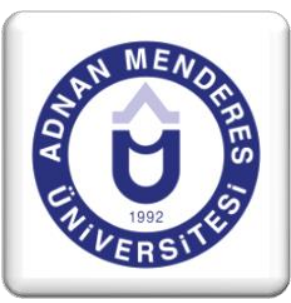

\title{
Güvenlik Politikalarının Konstrüktivist Bir Unsuru Olarak Güvenlik Kültürü ve Türkiye Örneği ${ }^{1}$
} Fikret BİRDIŞLí ${ }^{2}$, Aynur BAŞURGAN ${ }^{3}$

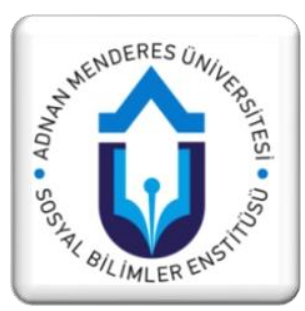

\section{ÖZET}

Güvenlik devletlerin dış politika davranışlarına yön veren, çok boyutlu ve multidisipliner çalışılması gereken kapsamlı bir konudur. Bu kapsamda devlet politikaları ile toplumun kültürü arasında bir etkileşim olduğu düşünülmektedir. Bu konuda yapılan çalışmalar Siyasal Kültür başlığı altında yürütülürken bu etkileşimin güvenlik politikalarındaki yansımalarını ifade etmek için Stratejik Kültür kavramı kullanılır. Fakat Stratejik Kültür devletin davranıș biçimini açıklarken toplumun dış dünya ile ilgili algı ve düşüncelerini ve nedenlerini içermez. Bu durumu açıklamak için bu çalışmada Güvenlik Kültürü kavramı tercih edilmektedir. Araştırmanın bulgularına göre toplumların Güvenlik Kültürü Toplumsal Biliş, Schizmogenesis veya Pygmalion Etkisi ve Kültürel Farklılıklara dayalı olarak biçimlenmektedir. Bu kapsamda siyasal elitler toplumun Güvenlik Kültürünü oluşturan bir sosyalizasyon süreci sonunda ortaya çıkan stratejik kültüre güvenlik ve dış politikalarını eklemleyerek ulusal ve uluslararası politikalarını yürütmektedirler. $\mathrm{Bu}$ sosyalizasyon süreci olgusal etmenlere dayalı olabildiği gibi algısal da olabilir. Bu teorik çerçeveyi bir örnek üzerinden somutlaştırmak üzere Türkiye ve Türk Dış Politikası örnek olay olarak ele alınmıştır.

Anahtar Kelimeler: Güvenlik Kültürü, Konstrüktivizm, Stratejik Kültür, Siyasal Kültür ve Ulusal Güvenlik.

\section{Security Culture as the Constructivist Elements of National Security Policies and the Turkey Case}

\begin{abstract}
Security is a comprehensive and multidisciplinary subject which is reference for the state policies. In this context, it's assumed that there should be a close relationship between culture of society and state policies. In this context, academicians use the concept of Political Culture to explain this relationship, but the Strategic Culture term has been coined to explain relevance with security policies. Nevertheless the concept of Strategic Culture also is insufficient to explain societal perception about security matters. So, the word of the Security Culture has been preferred to explain security matters in the societal dimension in this study. According to the findings, security culture is created by the constitution of the Social Cognition, Schismogenesis /Pygmalion Effect and Cultural Differences. Political elites maintain national and international policies by articulation of security and foreign policies to the Security Culture of society which is created by the special socialization process. Turkey and the Turkish Foreign Policy are considered as case studies to embody this theoretical framework through an example.
\end{abstract}

Key Words: Constructivism, National Security, Security Culture and Strategic Culture.

\footnotetext{
${ }^{1}$ Bu çalışma 27-29 Temmuz 2017 tarihleri arasında Adnan Menderes Üniversitesi tarafindan Aydın'da “EUREFE'17” isimli konferansta bildiri olarak sunulmuştur.

${ }^{2}$ Yrd. Doç. Dr., Kahramanmaraş Sütçü İmam Üniversitesi, İktisadi ve İdari Bilimler Fakültesi, Siyaset Bilimi ve Uluslararası İlişkiler Bölümü, fikretbirdisli@ hotmail.com

${ }^{3}$ Yüksek Lisans Öğrencisi, Kahramanmaraş Sütçü İmam Üniversitesi, Sosyal Bilimler Enstitüsü, Siyaset Bilimi ve Uluslararası İlişkiler Bölümü, aynuramektuplar@gmail.com
} 


\section{Giriş}

Güvenlik politikaları tüm devlet politikaları için referans rolü üstlenen üst düzey bir politikadır. Dolayısıyla ulusal güvenlik politikalarının oluşum süreci ve nitel analizi siyaset bilimi açısından önemli veriler barındırır. $\mathrm{Bu}$ nedenle uluslararası ilişkiler alanı içinde güvenlik çalışmaları öznel ve önemli bir yer tutmaktadır. Siyaset biliminin temel teorileri 1şığ1 altında güvenlik konusunda yapılan çalışmalar niteliksel olarak güvenliğin sağlanması, barış çalışmaları ve üçüncü dünya ülkeleri bağlamında ele alınan güvenlik sorunları olmak üzere üç sınıfa ayrılmaktadır (Bilgin, 2003: 203). Tüm bu çalışmaların ulaştığı ortak nokta ise barış ve güvenliğin sadece güç kullanarak sağlanamayacağı ve güvenliğin sadece savaş ve çatışma halinin olmaması anlamına gelmediğidir. Bu sonuç güvenlik konusunun multidisipliner ele alınması gereken çok boyutlu bir konu olduğunu ortaya koymuştur. Soğuk Savaşın sona ermesi ve siyaset biliminin klasik teorilerinin Sovyetler Birliğinin çöküş nedenlerini açıklamakta yetersiz kalması ise güvenlik üzerine çalışan uzmanları farklı arayışlara itmiştir. Bu arayışlar güvenliğe devlet merkezli bakışı zayıflatırken konuya toplum merkezli ve konstrüktivist (inşacı) yaklaşımları güçlendirmiştir. Güvenliğe konstrüktivist yaklaşımlar sadece istikrarlı güvenliğin nasıl sağlanacağı konusuyla ilgilenmekle kalmaz aynı zamanda güvensizliğin nedenleri üzerine de eğilir. Bu nedenle eleştirel güvenlik çalışmaları ve post-modern yaklaşımlar güvenlik literatürü içinde giderek artan bir hacme ulaşmıştır. Güvenlik çalışmalarındaki bu çeşitlenme güvenliğin kavramsal literatürüne de yansırken güvenlik konusunda ampirik çalışmaların sayısını da giderek artırmaktadır. Özellikle güvenliğin sosyal ve siyasal inşa boyutuyla ilgilenen uzmanlar kültür ve güvenlik politikaları arasındaki etkileşime de odaklanırken ulusal güvenlik politikalarının analizi sırasında siyasal kültür kavramının açıklamakta yetersiz kaldığı alanları tanımlamak için stratejik kültür kavramını ortaya atmışlardır (Lantis, 2002: 87).

Stratejik kültür kavramı uluslararası alanda devletlerin davranışlarının sosyal karakterine odaklanmakta, bu konuda yapılan akademik çalışmalar ulusal güvenlik politikalarının hangi düşünsel temele dayandırıldığı sorusuna cevap aramaktadır. Toplumun kültürel, tarihsel ve ekonomik değerleri ve moral kapasitesinin güvenlik politikalarını nasıl biçimlendirdiği ve desteklediği konusuna odaklanan bu yaklaşım kültürü verili olarak kabul etmekte, araştırmasını bu kültürün siyaset düzlemindeki yansımasına odaklamaktadır. Bu çalışmada ise stratejik kültür çalışmalarında verili olarak kabul edilen kültürün nasıl inşa edildiği sorusuna yanıt aranmaktadır. $\mathrm{Bu}$ bağlamda toplumu oluşturan bireylerin ve toplumun güvenlik konusunda dış dünyayı anlamak ve anlamlandırmak için sahip olduğu algı, norm ve değerleri ifade etmek üzere güvenlik kültürü kavramı tercih edilmiştir.

Çalışmanın temel varsayımı toplumun güvenlik kültürü ile ulusal güvenlik politikaları arasında karşılıklı bir etkileşimin bulunduğu, toplumun güvenlik kültürünün ise sosyolojik ve sosyal psikolojik unsurlar tarafindan inşa edildiği yönündedir. $\mathrm{Bu}$ bağlamda yapılan araştırmalar neticesinde toplumun güvenlik kültürünün bir sosyalizasyon süreci sonunda ortaya çıktı̆̆ bulgusuna ulaşılmıştır. Bu sosyalizasyon sürecini oluşturan sosyopsikolojik faktörler; toplumsal ya da sosyal biliş, schismogenesis ${ }^{4}$ veya pygmalion (beklenti) etkisi ve kültürel farklılıklardan oluşmaktadır. Çalışmanın genel ekseni bu faktörlerin açıklanması üzerine oturtulmuştur. Bu teorik çerçeveyi bir örnek üzerinden somutlaştırmak üzere Türkiye ve Türk Dış Politikası örnek olay olarak ele alınmış fakat güvenlik kültürü konusunda

\footnotetext{
${ }^{4}$ Schismogenesis kavramı antropolog Gregory Bateson (1936) tarafından 1930'lu yıllarda "bireyler arasındaki kümülatif etkileşimden kaynaklanan bireysel davranış normlarında farklılaşma süreci” şeklinde açıklanmıştır. Bu kavramın tam olarak Türkçe karşılığı yoktur. Bazı yerlerde sözlük anlamı üzerinden yapılan çıkarımlarla "bölünmenin yaratılması" ya da "ayrılarak yeniden doğma" gibi bir anlam verilmiştir. Kavramsallaştırma konusundaki bu belirsizlik nedeniyle bu çalışmada bu kavramın orijinal haliyle kullanımına karar verilmiştir.
} 
ulaşılan bulgular henüz sahada test edilmediği için fazla detaylandırılmamıştır. Dolayısıyla bu çalışma güvenlik çalışmaları içinde özgün bir kavram olduğu düşünülen güvenlik kültürü kavramının teorik olarak temellendirilmesi sorunsalına odaklanmıştır. Bu çalışmanın genel planı çerçevesinde öncelikle güvenlik kavramı, siyasal kültür ve stratejik kültür konusunda açıklamalar yapılıp ardından güvenlik kültürü tanımlanmaktadır. Makalede geçen sosyal psikolojiye ait pek çok kavramın Türkçede tam karşıllı̆ı bulunmadığından bu kavramların asıllarının kullanılması tercih edilmiştir. Araştırmada nitel ve betimsel araştırma yöntemlerinden yararlanılmıştır.

\section{Etimolojik ve Epistemolojik Açıdan Güvenlik, Ulusal Güvenlik}

Etimolojik olarak güvenlik pozitif rahatliktan negatife giden bir ivmeyi sembolize eder. Latince "secura" (se+cura) yani "kaygıdan uzak olmak" anlamındadır (McSwyeeney, 1999: 27).

Güvenlik kavramı tarihin başından bu yana hem bireysel hem de toplumsal alanda kullanılmış bir kavramdır. Bu sebeple güvenlik yaşamsal bir zorunluluk hali olup, en temel de bireyle başlamakta, yavaş yavaş halkalar şeklinde uluslararası sisteme kadar büyümektedir. $\mathrm{Bu}$ durumda temelde iki güvenlik yaklaşımından söz etmek mümkündür; devlet odaklı güvenlik yaklaşımı ve birey odaklı güvenlik yaklaşımı (Birdişli, 2016a: 21).

Güvenlik özünde tartışmalı bir kavramdır. Bu sebepledir ki güvenlik kavramının birçok tanımı mevcuttur ve her geçen gün bu tanımlara bir yenisi eklenmektedir (Brauch, 2008). Güvenliği uluslararası ilişkiler disiplininde kavramsal olarak ilk ele alan Arnold Wolfers'a göre güvenlik, objektif anlamda eldeki değerlere yönelik bir tehdidin olmaması, subjektif anlamda ise bu değerlere yönelik bir saldırı olacağı korkusu taşınmamasıdır (Wolfers, 1952: 150). Bu tanımlamadan yola çıkarak güvenlik olgusunun kökeninde "tehdit" kavramının var olduğu kabul edilmiştir. Bir devletin, toplumun ya da bireyin yaşamına veya sahip olduğu değerlere yönelik olumsuz sonuçlar doğurma potansiyeli olan olaylar ya da olgular "Tehdit" olarak tanımlanmıştır (Krahmann, 2005: 4). Herhangi bir çatışma durumunda, aktörlerin kendi çıkarlarını, diğer aktörlerin tehditlerine rağmen devam ettirebilmeleri ve koruyabilmeleri olarak tanımlanan güvenlik kavramını David Baldwin, "sahip olunan kazanımlara gelebilecek bir zararın en düşük olduğu hal" şeklinde tanımlamaktadır (Baldwin, 1997). Güvenlik bağlamında, korunmak istenen şeye katkı ve yarar sağlayacağ düşünülen her şey ise "çıkar” kavramı ile açıklanmaktadır (Birdişli, 2016a: 22).

Göreceli bir kavram olan güvenlik; uluslararası sistemin bütünün veya bütününe yakının güvenliği, coğrafi ya da işlevsel alt sistemlerin-bölgelerin güvenliği, devletlerin güvenliği, toplumun güvenliği, toplumsal alt grupların güvenliği ve bireylerin güvenliği gibi birkaç düzlemde ifade edilebilir (Dedeoğlu, 2003: 11-13). Barry Buzan'a göre ise asıl güvenlik "tehditten özgür kalabilme gayreti” dir (Buzan, 1983).

Genel olarak literatürde güvenlik ve ulusal güvenlik kavramlarının benzer anlamda kullanıldığını söylemek mümkündür, ancak kavramlar arasında amaç farklılıkları bulunmaktadır. Güvenlik kavramına ulusal sıfatının eklenmesiyle, kavram, ulus ve devlet arasındaki bağlantıyı vurgular hale gelmektedir. Ulusal güvenlik kavramı, güvenliğin objesinin, yani güvenliği tehdit altında olanın ve korunması gerekenin (referans nesnesinin) ulus olduğu algısını güçlendirmeyi amaçlamaktadır (Buzan, 1983: 70). Kavramların benzer olarak algılanmasının diğer bir sebebi; Realist ekolün güvenlik kavramına olan yaklaşımından kaynaklanır. Güvenliği devletlerin askeri güç kullanımından gelecek zararları savuşturma kabiliyeti olarak tanımlayan Realist düşünürler, çatışmaların ve savaşların 
nedenlerini araştırıp bulmayı da Güvenlik Çalışmalarının en temel uğraşısı olarak düşünürler (Walt, 1991: 212). Realistlere göre devlet, vatandaşlarının fiziksel güvenliğini bütünsel olarak sağlamak durumunda olduğundan, devletin güvenliği, aynı zamanda bireyin güvenliği olarak algılanır. Bu sebeple güvenlik kavramı, ulusal güvenlik kavramı ile eşanlamlı olarak kullanilır (Torun, 2012: 19).

Fransız İhtilali'nin ortaya çıkarttı̆̆ı siyasal düşüncelere dayanan, ulus düşüncesi aslında Birinci Dünya Savaşı sonrasında imparatorlukların çöküşüyle birlikte ortaya çıkan ulusçuluk fikrini temel alan bir olgudur. Tarihsel süreç içerisinde de her devlet kendi gerçeklerine uygun biçimde uluslaşmıştır. Fransız İhtilalinin beraberinde getirdiği düşünceler ve ulus devlet anlayışının güçlenmesi öncelikle Ülkesel Güvenlik (Territoryal Security) anlayışının ortaya çıkmasına neden olmuş ve bu anlayış devletin temel amaçlarından biri haline gelmiştir. Dolayısıyla ülke sınırlarını ve devletin egemenliğini korumayı amaçlayan bu teritoryal güvenlik yaklaşımı ulusal güvenlik anlayışının da temelini oluşturur (Birdişli, 2016a: 28).

Bir Amerikan terimi olan ve ilk kez ABD Başkanı Franklin Roosevelt döneminin Denizcilik ve Harry Truman döneminin Savunma Bakanı olan James Forrestal tarafından kullanıldı̆̆ iddia edilen (Del RossoJr, 1995: 183), ulusal güvenlik kavramının siyasette kullanımı ise dönemin kongresi tarafından çıkartılan "National Security Act" (Ulusal Güvenlik Yasası, 18 Ekim 1947) yasası ile başlamıştır (Wolfers, 1952: 482). Yasanın çıkış amacı; ulusal güvenliği ilgilendiren konularda tüm devlet kurumlarının Savunma Bakanlığı nezdinde, sivil denetim altında sevk ve koordine edilmesine olanak sağlayacak hukuki zeminin oluşturmaktır (Birdişli, 2016a: 98). Bu tarihten sonra ulusal güvenlik kavramılla birlikte ulusal güvenlik politikaları konuşulmaya ve belirlenmeye başlanmıştır (Wolfers, 1952: 452).

Ulusal güvenlik kavramının günümüzde anlaşıldığı şekliyle ortaya çıkışı ve evrensel bir boyut kazanması, İkinci Dünya Savaşı sonrası oluşan yeni uluslararası koşullarda gerçekleşmiş ve literatüre girmiştir (Sheehan, 2005:6; Mangold, 1990: 2). Soğuk Savaş döneminin parametrelerine uygunluk ve Realist kuramın alan içindeki üstünlüğüne bağlı olarak şekillenen ulusal güvenlik kavramı, belirtilen geleneksel anlamıla, korunması gereken değerler olan siyasal bağımsızlık ve toprak bütünlügünü içermektedir (Baldwin, 1997: 13). Ulusal güvenlik, bir devletin varlığını sürdürebilmesi için kendisine yönelen tehditleri nasıl algıladığını ifade etmekle birlikte, kavramının anlam ve içeriği zaman içerisinde değişmiştir (Torun, 2012: 18). Dolayısıyla, spesifik bir anlama sahip olmayan, kendisine atfedilen değerlere bağlı olarak anlam ve mana kazanan ulusal güvenlik, farklı boyutlarda tanımlanabilen bir kavramdır.

Örneğin, ulusal güvenlik kavramı sadece askeri boyuta indirgenerek ve olağan olmayan dönemlerde alınacak olan, önlemleri de kapsayacak biçimde dar anlamda kullanılabilmektedir. Bu anlamıyla ulusal güvenlik, kısa ve özlü bir ifadeyle, bir ülkenin iç ve dış tehditlerden korunması biçiminde tanımlanabilir. Daha genel anlamda ise ulusal güvenlik, devlet düzenini korumak amacıyla alınan her türlü önlem olarak anlaşılabilir. $\mathrm{Bu}$ açıdan ulusal güvenlik kavramı; bir devletin siyasi bağımsızlığını ve özgür karar verebilme yeteneğini silahlı kuvvetler, diplomasi ve istihbarat servisleri aracılığıyla sağlayabilmesi anlamına gelmektedir (Sheehan, 2005: 16).

Uluslararası İlişkiler disiplininin merkezi ve anahtar kavramlarından biri olarak ulusal güvenlik, bir devletin iç ve dış politika kararlarının alınmasında belirleyici faktördür. Karar vericiler, herhangi bir iç veya dış politika kararını ya da uygulamayı, ulusal güvenliğe aykırı olarak kendi kamuoyuna açıklayamaz ve savunamazlar (Walt, 1991: 212). Bu kapsam ve 
anlam derinliği içinde ulusal güvenlik aynı zamanda üst düzey bir politikanın (high politic) adidir.

\section{Güvenliğe Konstrüktivist (İnşaacı) Yaklaşım}

Ulusal güvenlik politikalarını şekillendiren yaklaşımlar İdealizm, Realizm, Liberalizm ve Marksizm başlıkları altında incelenmektedir. Güvenlik çalışmalarının sınıflandırılmasında ayrı bir kategori olarak ele alınan Konstrüktivizm (inşaacılık) ise başlı başına bir siyaset teorisi olmayıp idealizm içinde gelişen bir analiz yöntemidir (Birdişli, 2016a: 31).

İnşacılık kavramı, günümüz Uluslararası İlişkiler disiplinindeki yeri tartışılmakla birlikte disiplinin gelişmesi ve yeni konularda tartışma zemini hazırlaması açısından önemlidir. $\mathrm{Bu}$ kuram; eleştirel yaklaşım, sosyal inşacı kuram (Social constructivist) veya üçüncü tartışma olarak da adlandırılmıştır (Güner, 2008: 12-13). İnşaacılık kavramını, Uluslararası İlişkiler alanında ilk kez Nicholas Onuf kullansa da (1989: 2), onu popüler hâle getiren kişi Alexander Wendt'tir. Alexander Wendt'e göre (1999: 4) 1990'ların etnik, dinsel ve kültürel çatışmalarıyla yoğrulan bu karmaşık atmosferde, materyalist ve birey odaklı geleneksel uluslararası ilişkiler teorileri, sistemde oluşan beklenmedik ve büyük değişikliği açıklamakta yetersiz kalmıştır. İnşacılık materyalist söyleme karşı, kültürel yapıları birleştirerek anlamlandırmaya çalışan ve kimlik, farklılıklar gibi etmenleri göz önüne alarak kavramları açıklayan bir yaklaşımdır (Güner, 2008: 12-13). Böylelikle "güç", "güvenlik", "tehdit" ve "çıkar" gibi, realizmin oldukça popüler kavramlarının yanı sıra, arka plana itilmiş "kültür" ve "kimlik" gibi kavramlar da ele alınmaya başlanmıştır (Sarı Ertem, 2012: 182).

İnşacı akademisyenler, uluslararası toplumun sadece devletin davranışlarını sınırladığını değil, bireylerin ve toplumunda sosyal kimliklerini oluşturması için zemin hazırladığını söylemektedirler. Bu yüzden insan tercihlerini anlamak için bu yaklaşım, çerçevesinde insan çıkarlarını ve onların bu hareketlerini düzenleyen, süreci etkileyen normların, kuralların ve kimliklerinde nasıl oluşturulduğunu anlamamız gerektiğine dikkat çekerler. İnşacı yaklaşımı benimseyen yazarlar ulusal çıkar, güç, anarşi, güvenlik ikilemi gibi kavramları ve sistemin diğer içinde barındırdığı kavramları, sistemin yapısının bir sonucu olmaktan ziyade sistem içerisinde sosyal olarak inşa edilmiş olduklarını savunurlar (Holtsi, 1989: 19). Sosyal İnşacı akademisyenler, devlet faaliyetlerinin ve uluslararası kurumların anlaşılması için kolektif kültürel-kimliksel öngörülerin veya kabullerin incelenmesi gerektiğini savunurlar. Devletlerin karşılıklı ilişkilerinden etkilenerek oluşan tarihsel ve kültürel kimliklerin ülke çıkarlarını ve davranışlarını etkilediğini öngörürler (Dağı, 2007: 134). Bütün devletlerin objektif olarak tanımlanan milli çıkarlarının peşinde koştukları ve bu hedefler uğruna güvenliklerini azami derecede arttırmaya çalışan realizme karşın, konstrüktivistler milli çıkarları hem devletleri hem de içinde bulundukları yapıyı dönüştüren pratiklerin bir ürünü olarak görmektedir. Doğal olarak milli çıkarların ve buna bağlı olarak güvenliğin hangi durumlarda şekilleneceği her şahsın bakış açısına göre değişecektir. Bu bakış açısı kimliklere göre değişiklik göstereceğinden, tarihi, kültürel, siyasi birikim, farklı toplumların aynı olaylara değişik açılardan bakmasını açıklar. Weldes devletlerin güvenlik tehditlerini farklı kimliklerin neticesi olarak ortaya çıkan bir güvensizlik durumu olarak görmektedir. Ona göre, "güvensizlik; benlik ve öteki veya ötekilerin ayrımının yapılabildiği bir kimlik oluşumu sürecinin sonucudur..." kısacası kimlik ve güvensizlik birbirini dönüştüren kavramlardır (Çalış vd., 2001: 334).

Ayrıca devletler uluslararası sistemde tek aktör olarak kabul edilmezler. Bu durumda güvenlik içinde harekete geçen aktörler çeşitlidir. Dolayısı ile realizmin aksine milli çıkarlar, soyut veriler olarak ele alınmaz. Bütün bu yapının belirli bir siyasi ve sosyokültürel inşa sürecinden geçerek bu hale geldiğine dikkat çekilir (Dağı, 2007: 134). İnşacı akademisyenler 
güvenlik sorunlarının ekonomik, askeri veya maddi bir alt yapısı olduğunu kabul ederler fakat temelinde yatan şeyin normlar ve değerler gibi ideal düşüncelerden kaynaklandığına vurgu yaparlar (Güner, 2008: 14).

\subsection{Siyasal Kültür ve Güvenlik}

Ulusal güvenlik politikalarına etki eden inşacı unsurlar genellikle siyasal kültür ekseninde ele alınmaktadır. Siyasal Kültür kavramı ilk kez 18.yüzyılın sonuna doğru Johann Gottfried Herder ve Wilhelm von Humboldt'un eserlerinde geçmektedir (Barnard, 1969; Lipp, 1996). Ancak siyasal kültürün bir kuram olarak ortaya çıkışı Gabriel A. Almond ve Sidney Verba'nın 1963 yılında yayınladıkları 'The Civic Culture' çalışması ile mümkün olmuştur (Almond ve Verba, 1963). Almond ve Verba, II. Dünya Savaşı'nın geride bıraktığı ve siyaset bilimciler için çözülmesi gereken, "demokrasilerin istikrarlı olmasının ya da çökmesinin neye bağlı olduğu" sorusunun cevabının, siyasal-kültürel olduğunu düşünmüşlerdir. $\mathrm{Bu}$ düşünce onları beş ülkede (ABD, İngiltere, Almanya, İtalya ve Meksika) yürütülen kapsamlı bir çalışma yapmaya yöneltmiştir. Böylece Almond'un ilk kez 1956 yılında ortaya attı̆̆ 1 ve "her siyasal sistemin siyasal eylem bakımından oryantasyonların belirli bir kalıbında yerleşmiş" olduğunu iddia edip bunu siyasal kültür olarak tanımladığı kavram, bir yaklaşım ya da bir kuram olarak siyaset bilimine giriş yapmıştır (Almond, 1956). Bir başka çalışmasında ise, siyasal kültürü kısaca 'siyasetin sübjektif boyutu' olarak tanımlamıştır (Almond, 1989).

Siyasal kültür hakkında en yaygın ve bilindik tanım Almond ve Verba tarafindan (1963: 1114) ortak olarak yapılan "siyasal kültür, devletlerin politik davranışlarını etkileyen bir toplumun siyasal sistemle ilgili inanç ve değerler dizesi”" açıklamasıdır. Dolayısıyla siyasal kültür, dış dünyayı algılama konusunda, fikir, inanç ve ahlak gibi normatif değerlerin yanı sıra bireysellik ya da toplumsallık gibi genel eğilimleri, demokrasi kültürü ve kurumlar gibi daha somut görünümleri de içermektedir. Bu görünümler aynı zamanda uluslararası alanda ülkenin arzu edilen konumunu ya da uluslararası toplumda benimsenen ideal rolünü içeren ampirik ve bilişsel etmenlerdir. Bu nedenle siyasal kültür diş politikada olduğu gibi güvenlik politikalarının da en önemli açıklayıcı nedenlerinden biridir (Lantis, 2002: 90).

Almon ve Verba'ya göre (1963: 11-14) bir toplumun demokrasi, kurumsallik, ahlak, bireysellik ya da toplumsallık anlayışı ile askeri gücün kullanımı konusundaki anlayışı siyasal kültürü biçimlendirmektedir. Dolaysıyla her ulusun siyasal kültürü ile güvenlik politikası arasında bir ilişki olmalıdır (Birdişli, 2016b: 641).

Bir toplumda siyasal kültür, toplumu oluşturan üyelerin siyasal nesneler karşısındaki tutum, davranış ve eğilimlerinden oluşur. Siyasal kültür kavramı bir toplumun ideolojisi, kimliği, değerleri, gelenekleri ve siyasi rollerini incelemek için ortaya atılmıştır. Siyasal kültür siyasal sistemleri anlamak ve siyasi olayları analiz etmek için kullanılmaktadır (Sosyal Bilimler Ansiklopedisi, 1991). Bir devletin sahip olduğu siyasal kültür o ülkenin dış politika yapım sürecinde önemli rol oynamaktadır. Kültür kavramı paylaşılan değerleri, gelenekleri ve sembolleri kapsamaktadır. Bu bağlamda semboller, efsaneler, gelenekler, inançlar ve alışkanlıkların, diplomaside karar alıcıların tehdit algısı, güvenlik, barış, istikrar ve çıkar algısı gibi kavramları tanımlamalarında yönlendirici olduğu söylenebilir. Ülkedeki siyasal ve diplomatik kültür, aktörlere ne yapmaları gerektiği konusunda yol göstermektedir (Arı, 2001: 135). Bu bağlamda belirlenen öncelikler, reel politikanın yanı sıra kültürel inşa boyutuna da sahiptir. Bu nedenle güvenlik çalışmalarında siyasal kültürün taşıdığı önem göz ardı edilmemelidir. 


\subsection{Stratejik Kültür}

Siyasal Kültür tanımlamaları, siyasal davranışı açıklarken güvenlik politikaları için yetersiz bulunmuş ve çoğu yerde bu kavram yerine, Jack Synder tarafından geliştirilen stratejik kültür kavramı tercih edilmiştir (Lantis, 2002: 87). Jack L. Snyder (1977: 8), stratejik kültürü "stratejik bir toplumun üyelerinin, stratejik tercihle ilgili eğitim ya da taklit yoluyla edindikleri ve birbirleriyle paylaştıkları alışılagelmiş davranış kalıplarının, şartlı duygusal reflekslerin ve fikirlerin toplamı olarak" tanımlamaktadır. Stratejik kültür "güvenlik hedeflerini elde etmek için uygun amaç ve araçları belirleyen, kolektif kimliği ve diğer gruplarla ilişkileri biçimlendiren, ortak tecrübeler ve (hem sözlü hem yazılı) kabul edilen öykülerden türemiş ortak davranış biçimleri, varsayımlar ve inançlar sistemidir" (Johnson et al., 2009).

Kavramsal olarak inşacı yaklaşımın bir ürünü olan stratejik kültür, tarihsel tecrübenin bir yansıması olarak kabul edilebilir (Gray, 1984: 28). Ken Booth'a göre stratejik kültür; tarihten, coğrafyadan ve siyasal kültürden türetilen bir kavramdır. Stratejik kültür savaş ve barış hakkındaki davranışlara yön veren bir olgudur. Booth'a göre stratejik kültür aktörlere uluslararası politikada kuvvet kullanımı, sivil-asker ilişkileri ve stratejik doktrinler gibi konularda, aktörlerin davranışlarının şekillenmesinde önemli bir rol oynar (Booth, 2005: 2526). Colin Gray stratejik kültür kavramının "kendimizi, ötekini ve ötekinin kendimiz hakkındaki düşüncesini daha iyi kavramada kullanışlı bir araç" olduğunu iddia etmiştir (Gray, 1984: 26).

Tarihsel gelişmeler, çatışmalar ve siyasi olaylar, insanlar, toplumlar ve devletlerarasındaki ilişkilerin anlaşılması çerçevesinde, kültürün rolünün önemli olduğu anlaşılmıştır (Uz Zaman, 2009: 69). Stratejik kültür yaklaşımına göre uluslararası sistemde devletlerin stratejik tercihlerinin kaynağı, düşünsel ve kültürel alanlarda aranmalıdır. Stratejik kültür yaklaşımında stratejik çevreyi oluşturan semboller sistemi, bir devletin savaş ve çatışmaya yönelik düşünceleri ile ilgili geliştirdiği metafor ve tasvirlerin temel varsayımlarından meydana gelir. "Stratejik kültür, devletlerin uluslararası sistemin eşit olmayan kuvvet dağılımındaki değişiklikleri yorumlayan/anlamlandıran bir prizma olarak görülebilir" (Kardaş, 2007: 141).

Devletlerin güvenlik ve dış politika tercihlerinin arka planında yer alan norm ve mitlerin oluşumu ve karar alma sürecindeki etkileri araştırılırken, devletlerin sahip oldukları stratejik kültürlerinin incelenmesi gerekir. Aktörler ulusal ve uluslararası sorunların çözümüne yönelik tercihlerinde ve zihinsel arka planlarında yer alan, kültürel derinliklerinin etkisi ile birlikte yönelimler belirlemekte ve böylece stratejik kültürlerini oluşturmaktadırlar. Ortaya çıkan bu stratejik kültürler devletlerin tutum ve davranışlarını etkileyebildiği ölçüde önemlidir (Erdağ, 2011: 57). Kültür sadece devletlerin davranışlarını etkilememekte aynı zamanda devletlerin karakter tipi özelliklerini iç ve dış politikayı kapsayacak şekilde biçimlendirmektedir (Jepperson et al., 1996).

Ulusal güvenlik ve savunma politikalarının stratejik kültür ve normlar bağlamında ele alınması, geçmişin 'olduğu' gibi değil, toplumlar ve onların yönetici ağları (ruling networks) tarafından nasıl algılandığını anlamaya imkân sağlamaktadır. Stratejik kültür, güvenlik ve savunma politikalarında ülkeler için bir çeşit pusula görevi görmektedir. Devletin kendisi hakkında sahip olduğu algı (dünyadaki rolü, tehdit algılaması, gücün kullanımına ilişkin meşru kabul edilen amaç ve araçlar) tarihsel bir süreç içinde oluşmuş ve stratejik kültürünün de etkisiyle günümüzdeki politikalarına yansımıştır (Meyer, 2006). 
Kültür kavramın stratejik tercihler üzerinde biçimlendirici bir etkisi olduğu tartışmalarının başlamasıyla çeşitli kültürel teoriler ve güvenlik kültürü gibi kavramlar ortaya çıkmıştır (Desch, 1998: 142).

\section{Güvenlik Kültüirü}

Pek çok yazar tarafından uluslararası güvenlik çevriminin materyal olgulardan ziyade kültürel öğeler tarafından biçimlendirildiği düşünülmekte ve savunulmaktadır (örn. Katzeinstein P., 1996; Went A., 1999; Kier E., 1996). Özellikle 1990 yıllarının başında Sovyetler Birliği'nin beklenmedik biçimde dağılması ve bu sonucun siyaset biliminin klasik teorileriyle açıklanmasının zorluğu, bilim dünyasını alternatif arayışlara sürüklemiş ve yapısalc1, inşacı (konstrüktivist) teoriler ilgi görmeye başlamıştır. Bu teorilerde kültür, siyasal davranışı açıklamak için kullanılan önemli bir öğedir. Kültürel öğeler sadece ulusal düzeyde olmayıp uluslararası ilişkilerde de açıklayıcı bir fenomen olarak kabul edilir. Fakat kültüre dayalı olarak yapılan açıklamaların bir yönü, iç politikanın devlet davranışını ve dış politikayı biçimlendirdiği yönünde konstrüktivist bir yaklaşımdır. Diğeri ise uluslararası ilişkileri biçimlendiren sosyolojik bir ortamın varlığıdır.

Bu konuda yapılan çalışmalardan biri olan Katzenstein'in "The Culture of National Security" kitabında bu ortama "uluslararası kültürel çevrim (international cultural environment)" denilmektedir. Katzenstein (1996: 8) ve arkadaşlarına göre bu kültürel çevrimi oluşturan üç tabaka uluslararası sistem içinde gözlemlenebilir. Bunlar;

a) Uluslararası kurumlar

b) Uluslararası siyasal kültür

c) Uluslararası alanda cari olan dost ve düşman paternidir.

Uluslararası kültürel çevrimi biçimlendiren uluslararası kurumlar; NATO, AGİT, Şangay İşbirliği Örgütü, Bağımsız Devletler Topluluğu gibi güvenlik temelinde işbirliğine dayalı uluslararası örgütlenmeler ile uluslararası hukuk ve normalar kapsamında biçimlenmiş olan silahsızlanma rejimi, nükleer silahların yayılmasını önleme, sınır aşan suçlarla mücadele ve terörle mücadele vb. uluslararası rejimlerden oluşur. Dolayısıyla uluslararası güvenlik çevriminin ilk tabakasını oluşturan kurumlar, uluslararası örgütler ve rejimlerden müteşekkildir.

Uluslararası siyasal kültür ise başta uluslararası hukuk olmak üzere bağımsızlık ve egemenlik konusunda uluslararası alanda kanıksanmış normlar, uluslararası alanda benimsenmiş ve standartlaşmış müzakere koşulları, giderek birbirine eklemlenerek küreselleşen ekonomi politikaları ve organizasyon teorileri ile daha çok uluslararası af örgütü, insan hakları izleme komiteleri, çevre örgütleri gibi NGO'lar tarafından yürütülen transnasyonal siyasal tartışmaların etkileşiminden oluşmaktadır.

Üçüncü tabaka ise uluslararası alanda cari olan dost ve düşman paternidir. Dost ve düşman paterni için sabit bir tanım ve kural getirmek oldukça zordur. Çünkü uluslararası ilişkilerde bir devlet için tehdit olarak görülen diğer bir devlet yada başkaları için müttefik olabilmekte ve bu konsept sürekli yer değiştirebilmektedir. Katzenstein (1996: 3)'e göre bu otonomi güç politikasının doğurduğu bir epifitten kaynaklanıyor.

Bunların dışında literatürde ulusal güvenlik kültürünün uluslararası sistemin anarşik yapisindan (Waltz, 1979: 74-77), uluslararas1 rejimlerden (Krasner, 1983: 362-364) veya uluslararası ilişkilerin sosyolojik yapısından (Keohane, 1990: 183) etkilendiğini ileri süren pek çok argüman bulunmaktadır. 
$\mathrm{Bu}$ yaklaşımların tümü ulusal güvenlik çevriminin veya bir tür uluslararası kültürü doğuran sosyolojik/sosyopolitik ortamın dış etkenler tarafindan nasıl biçimlendiğini açıklamaya yönelik çabaları içermektedir.

$\mathrm{Bu}$ çalışma da ise uluslararası alanda var olduğu düşünülen uluslararası sosyolojik ortamdan veya bir uluslararası kültürel çevrimden ziyade, devletlerin dış politikalarına etki eden ulusal sosyolojik/sosyopolitik ortama odaklanılmaktadır. Fakat bununla birlikte bu çalışma bir siyasal kültür çalışması da değildir. Siyasal kültür güvenlik çalışmalarında da açıklayıcı bir kavram olarak kullanılmasına rağmen onun yerine daha öznel bir yaklaşım içeren güvenlik kültürü kavramı tercih edilmiştir. Literatürde Güvenlik Kültürü kavramı genel bir betimleyici kavram olarak görülmüş ve güvenlik politikalarına olan yaklaşımın niteliğine göre daha farklı kavramlara yönelinmiştir. Örneğin bunlardan biri Snyder tarafindan 1970'li yılların sonlarına doğru ortaya atılmış olan stratejik kültür kavramıdır.

Stratejik kültür kavramı öncelikle güvenlik çalışmalarını siyasal kültür üzerine yapılan siyaset bilimi çalışmalarından ayırmaya yarayan bir kavram olarak ortaya çıkmış ve Sovyetler Birliği ile ABD arasındaki nükleer rekabette tarafların uluslararası alandaki tutumlarını analiz etmek için kullanılmıştır. Bu nedenle stratejik kültür kavramı güvenlik politikalarını ulus devlet üzerinden çözümleyen devlet düzeyinde ve kolektif bir üst bakış sağlar.

$\mathrm{Bu}$ çalışma ise güvenlik politikalarını toplum düzeyinde analiz etmeyi amaçlayan bir yaklaşıma sahiptir. Bu nedenle stratejik kültür kavramı yerine güvenlik kültürü kavramı tercih edilmektedir. Bu çalışmada kullanılan güvenlik kültürü kavramı bir toplumun güvenlik konusundaki alg1 ve tutumunu betimleyen öznel bir kavramdır ve bu kavram altında güvenlik politikaları ile etkileşim içinde bulunan güvenlik konusundaki toplumsal alg1 ve tutumun analiz edilmesi amaçlanmıştır. $\mathrm{Bu}$ bağlamda Güvenlik Kültürü'nün yapısal unsurlarını açıklamaya girişmeden önce bir tanım yapmak yerinde olacaktır. Kısaca güvenlik kültürü, dış politika ile etkileşim içinde olan, bir toplumun dış dünyayı algılama biçimine dayalı kolektif dost ve düşman tanımı ve milli benlik paternidir. Bu nedenle güvenlik kültürü sadece başkalarını nasıl gördüğünüzü değil kendinizi de nasıl gördüğünüzü de içeren sosyal bir biliş içerir. Güvenlik kültürünün sosyolojik ve politik olmak üzere iki inşa boyutu bulunmaktadır.

\subsection{Güvenlik Kültürünün Sosyolojik İnşa Boyutu}

Güvenlik kültürü siyasal kültürün bir görünümüdür. Almond ve Verba siyasal kültürü, devletlerin politik davranışlarını etkileyen toplumun inançlar ve değerler kümesi olarak tanımlamaktadırlar (Almond ve Verba, 1963: 11-14). Dolayısıyla siyasal kültür, dış dünyayı algılama konusunda, fikir, inanç ve ahlak gibi normatif değerlerin yanı sıra bireysellik ya da toplumsallık gibi genel eğilimler ile demokrasi kültürü ve kurumlar gibi daha somut görünümleri de içeren kolektif bir algıdır.

Siyasal kültür iç ve dış politikada siyasal davranışı açıklamak için kullanılırken, Jack Snyder (1977) siyasal kültürün güvenlik politikaları için de oldukça açıklayıcı olduğunu düşünmüş ve daha özel bir kavramla bunu derinleştirmek istemiştir. Bu kapsamda Snyder 1970'lerin sonuna doğru stratejik kültür kavramını ortaya atarak siyasal kültürün geniş kavramsal çerçevesini daraltmaya çalışmıştır. Böylelikle güvenlik konusundaki ulusal stratejilerin dayandırıldığ "politik" sosyalizasyon sürecine odaklanma imkanı bulmuştur (Lantis, 2002: 93). 
Stratejik kültürle ilgili analitik çalışmalar işe, siyasal kültür bağlamında politikayı etkileyen kültürel etmenleri açıklayarak başlar. Buna göre politikayı etkileyen kültürel etmenler (Swidler, 1986: 273):

a) Genel inanç, tutum ve davranış paternleri

b) Sembolik araçlar

c) İnanç ritüelleri

d) Sanat formları

e) Törenler

f) Kültürel pratikler (dil, söylemler, hikâyeler ve günlük yaşama dönük ritüeller) gibi faktörlerden oluşur.

Stratejik kültürü etkileyen ya da biçimlendiren faktörler ise Snyder (1977: 94) tarafından şu şekilde sıralamıştır:

a) Algilanan tehditler

b) Teknolojik gelişmeler

c) İnanç ve tutumlarla iç içe geçmiş güçlü bilişsel kapasite

d) Tarihsel miras (etnosentrizm, eksepsiyonalizm, tarih vizyonu)

e) Politika yapım sürecinde yer alan diğer kurumların ve ordunun siyasette rolü konusundaki yaygın toplumsal kanaat ve inançlar.

Her iki sınıflandırmada yer alan faktörler dikkate alındığında gerek siyasal kültür ve gerekse stratejik kültürün ortak kesişim alanında algı ve inançların önemli yer tuttuğu görülmektedir. Diğer faktörler incelendiğinde ise stratejik kültürün iç politikanın durumuna göre daha öznel ve daha edilgen, güvenlik politikaları üzerindeki etkisinin ise yarı kalıcı (Semipermament) olduğu düşünülmektedir (Gray, 1984: 36-37). Bu açıklamalardan yola çıkıldığında toplumun güvenlik algısının nasıl ve hangi faktörlere dayalı olarak biçimlendiği ya da stratejik kültürün bağımsız ve bağımlı değişkenlerinin neler olduğu bu bölümün temel konusu olarak ortaya çıkmaktadır.

$\mathrm{Bu}$ makalede yer alan güvenlik kültürü kavramıyla, güvenlik çalışmalarında bağımsız değişken olarak görülen stratejik kültürün dayandırıldığı sosyolojik ve sosyal psikolojik aktörlerin açıklanması amaçlanmaktadır. Özetle siyasal kültür devlet davranışının dayandırıldığı sosyolojik form; stratejik kültür, sosyalizasyon sürecinin ortaya çıkarttığı algıya dayalı, ulusal güvenlik konusundaki davranış paternleri; güvenlik kültürü ise bu davranış paternini biçimlendiren sosyopsikolojik değişkenlerdir. Bir toplumun güvenlik kültürünün analiz edilmesi gerek toplumun sosyal dokusunu gerekse güvenlik politikasının gerçek hedeflerini açıklamak için büyük önem taşır.

Strateji çalışmalarında sıklıkla atıf yapılan Clausewitz herhangi bir savaşta üç unsurun önem taşıdığını vurgular. Birincisi savaşın amaçlarını belirleyen hükümetler, ikincisi bu amaç doğrultusunda savaşan ordular ve üçüncüsü bunları destekleyen insanlardır. Bu nedenle Clausewitz liderlerin mobilize olmuş kitlesel toplumların gerçek potansiyelini göz ardı etmemeleri gerektiğini özellikle vurgular (Howard, 1991: 28). Dolayısıyla toplumdaki genel kanaat üzerine oluşturulmuş siyasal koşulların nükleer stratejiyi bile belirleyecek kuvvete malik olduğu uzmanlar tarafindan vurgulanırken, Snyder (1977: 8) da elitlerin özel bir sosyalizasyon sonucu ortaya çıkan bir stratejik kültürü güvenlik ve askeri konulara eklemleyerek ulusal ve uluslararası politikalarını yürüttüklerini ileri sürmektedir.

$\mathrm{Bu}$ anlatılardan yola çıkarak güvenlik kültürünün sosyalizasyon sürecini oluşturan sosyopsikolojik faktörleri şu şekilde sıralayabiliriz: 
a) Toplumsal ya da Sosyal Biliş

b) Schizmogenesis ya da Pygmalion (beklenti) etkisi

c) Kültürel farklılıklar

\subsubsection{Toplumsal ya da Sosyal Biliş}

Sosyal dünya üzerinde düşünme biçimimiz, davranışlarımızı da belirleyen en önemli etkenlerin başında gelir. Dış dünyayı anlamak ve anlamlandırmak için bilgiye ihtiyacımız vardır. Fakat bilginin bizatihi kendisi iş görmez. Bu bilgiyi nasıl seçtiğimiz, hangi yollarla topladığımız, yorumladığımız, anımsadığımız ve nasıl kullandığımız önemlidir. Bu konuda temel varsayım, insanların genellikle dünya hakkında doğru izlenimler edinmeye çalıştıkları ve çoğu zaman bunu başardıkları yönündedir (Aranson vd., 2012: 122).

İnsanların dış dünyadan algıladıkları bilgi doğrultusunda sahip oldukları düşünce ve edindikleri izlenimleri Toplumsal ya da Sosyal Biliş olarak adlandırılır. Herkes yaşadığı sosyal dünyayı elinden geldiğince doğru algılamaya çalıştığı sırada bile birçok açıdan yanılabilir, yanlış izlenimlere kapılabilir. Kimi zaman yaşadığımız sosyal dünya ile ilgili beklentilerimiz de onu doğru algılamamızı engelleyebilir, hatta bu beklentilerimiz bizi koşullandırarak içinde bulunduğumuz sosyal dünyanın doğasını değiştirebilir. İçinde yaşadığımız dünya hakkındaki bu güdümlü düşünüşün temel nedenleri aşağıdaki güdülerden kaynaklanır (Aranson vd., 2012: 61).

a) Kendimizle ilgili olumlu bir görüşe sahip olma gereksinimi yani öz saygı

b) Dünyayı doğru görme gereksinimi yani sosyal biliş

c) Kendi çevremiz üzerinde belirli bir oranda kontrol sahibi olma gereksinimi yani otonomi

Sosyal psikoloji uzmanlarına göre, bu güdülerin sevkiyle yaşanılan dünyanın keşfi ve anlaşılması yönündeki çabanın kaynağı olan iki farklı sosyal biliş türü vardır. Birisi Hızlı ve Otomatik Düşünme diğeri ise Kontrollü Düşünmedir. Bu iki düşünüş biçimi doğrultusunda yaşadığımız dünyayı algılar ve ona uygun tavırlar sergileriz. Bu düşünüş biçimi, algı ve tutumlarımız bizim için kültürel bir çerçeve çizer.

\section{Hızlı ve Otomatik Düşünme}

Hızlı ve otomatik düşünme düşük eforlu bir düşünme biçimidir. Bilinçdışı, kasıtsız, istemsiz bir düşünme biçimi olarak da tanımlanır. Hızlı ve otomatik düşünme karşılaştı̆̆ımız yeni durumları önceki deneyimlerimiz ile bağlantı kurarak anlamamıza yardım eder. Dolayısıyla bir konu hakkında daha önce edindiğimiz bilgiler, yaşam tecrübelerimiz ve kanaatlerimiz yeni durumları anlamamızı kolaylaştıran zihinsel şemaları oluşturur. ${ }^{5}$ Başka bir ifade ile zihinsel şemalarımız karşılaştığımız durumlara yönelik ilk tepkilerimizi belirleyen hızlı, kısa yollardır. Sosyal grupları algılarken kullandığımız şemalara ise stereotip (kalıp yargı) denilir (Aranson vd., 2012: 125-126). Örneğin "pis Arap", "Barbar Türk", "cimri Yahudi" gibi olumsuz imajlar veya "çalışkan Japonlar", "zeki Almanlar", "kurnaz ve hileli İngilizler" gibi olumlu imajlar; "kızlar pembe giyer", "erkek çocuk oyuncak olarak araba veya silahla oynamayı sever" gibi yargılar yaygin stereotiplerdir.

Bir konu hakkında üzerinde fazla düşünmeden karar verdiğimiz durumlarda bu şemalar ve stereotipler işimizi kolaylaştırır. Şemalar bilgi eksikliğinin olduğu konularda boşlukları hızlıca doldurmamızı, yaşadıklarımıza zahmetsizce anlam vermemizi sağlar. Bu kapsamda

\footnotetext{
${ }^{5}$ Şemalar ve streotipler (kalıp yargı) önyargı anlamına gelmez. Ön yargılar tutumların duygusal bileşenlerine sahiptir. Şemalarda ise genellikle bu duygusal bileşenler bulunmaz. Önyargı bir tutumdur şemalar ise bilgileri etkileyen zihinsel yapılardır.
} 
şemalar olup biteni anlamamıza yardım ettikleri için özellikle karmaşık durumlarda yararlı olurlar. Dolayısıyla bir konu hakkında bilgimiz ne kadar az ve belirsiz ise boşlukları doldurmak için şemalara, stereotiplere o kadar çok başvururuz.

Şemalar ve streotipler kendi hayat tecrübemiz doğrultusunda oluşturulabildiği gibi dişarıdan yapılan girdilerle de oluşturulabilir. Örneğin Herold Kelley (1955) tarafindan yapılan bir alan araştırmasında öğrencilere, kendilerine sunum yapacak öğretmen hakkında bilgi içeren kısa bir biyografik not dağıtılır. Öğrencilerin bir kısmına verilen notta öğretmenin kişiliği ile ilgili "cana yakın", "üretken", "eleştirici" ve "pratik" birisi şeklinde bilgi paylaşımında bulunulur. Diğer kısmına verilen notta ise öğretmen hakkında "oldukça soğuk", ciddi" vb. tanımlamalarda bulunulur. Öğretmenin herkese yaptığı yirmi dakikalık bir sunumdan sonra öğrencilerden izlenimlerini değerlendirmeleri istenmiştir. Sonuçlar incelendiğinde öğrencilerin biyografik notta verilen şemayı boşlukları doldurmak için kullandıkları saptanmıştır. Ellerindeki notta öğretmen için "cana yakın", "üretken", "pratik" yazan öğrencilerin öğretmeni değerlendirmeleri bu yönde olurken, diğerleri aynı öğretmeni "soğuk" ve "mesafeli" bulmuşlardır. Bu ve benzeri pek çok alan araştırması dişarıdan aldığımız bilgilerin şema veya stereotip olarak yaşadığımız dünyayı algılama noktasına hizmet ettiğini ortaya koymuştur.

Şemalar ve stereotipler yaşadığımız sosyal dünya ile ilgili bilgilerimizi ve tutumlarımızı düzenleyen zihinsel yapılar olduğundan, güvenlik kültürü açısından önemi büyüktür. Çünkü Uluslararası politika toplumun geneli için anlaşılması zor olgu ve olaylarla doludur. $\mathrm{Bu}$ durumda siyasetçiler toplumda yer edinmiş şema ve stereotipleri kullanılarak ya da şema ve stereotipleri oluşturarak yürüttükleri politikalara toplumsal desteği artırabilirler. Örneğin; bir devlete ya da topluma yönelik oluşmuş tarihsel düşmanlık ya da güvensizlik o devlete karşı hükümetçe yürütülen politikalarda katalizör rol oynamıştır. Bu kapsamda Soğuk Savaş yıllarında ABD'nin Sovyetler Birliği'ne yönelik politikaları ve hükümetler tarafindan yürütülen nükleer programlar zihinsel şemalar ve streotipler sayesinde toplumda kolaylıkla destek bulmuştur.

Hızlı ve otomatik düşünmede yararlanılan yollardan bir diğeri de zihinsel stratejilerden ve kısa yollardan yararlanmadır. Günlük yaşamımızda yaptı̆̆ımız seçimlerin çoğunda tüm seçenekleri uzun uzadıya incelemeyiz. Bunun yerine kararları kolaylaştıran zihinsel stratejilerden ve kısa yollardan yararlanırız. Bu stratejiler her zaman en iyi karara varmamızı sağlamaz ama bizi kararsızlığın gri alanlarından kurtararak makul zamanlar içinde bir sonuca ulaşmamızı sağlarlar. Bu kısa yollar sezgisel kestirmelerden oluşur. İngilizce' de bu durumu ifade etmek için "Heuristic" kavramından yararlanılır, bu kavram Yunanca' da "keşfetme" anlamına gelir. Bir yargının akla en kolay gelen düşünceye dayandırılması "sezgisel kestirme" anlamına gelir. Örneğin; hekimlerin bir hastalığa tanı koyarken sezgisel kestirme yollara başvurduğu sıklıkla görülür. Uluslararası politika ve güvenlik konusunda insanlar karşılaştıkları durumları, zihinsel stratejiler üzerinden anlamlandırır. Dış politika alanında bir ülke ile yaşanan problemde sorunun kaynaklarını irdelemek ya da proaktif düşünmek yerine sorunun örneğin, Hristiyan-Müslüman çatışması ya da Doğu-Bat1 rekabeti gibi nedenlere bağlanması zihinsel stratejilere bir örnektir.

\section{Kontrollü Düşünme}

Kontrollü düşünme ise bir durumu yavaş ve dikkatli bir biçimde değerlendirip analiz etmeyi gerektirir. Bu nedenle kontrollü düşünme bilinçli, kasıtll, istemli ve eforlu düşünme olarak tanımlanır (Aranson vd., 2012: 164).

Toplumsal ya da Sosyal bilişte kültürel farklılıkların da etkisi görülür. Yani genel olarak insanların dünyaya yönelik bazı temel algılama ve düşünme biçimleri kültürden etkilenir. 
Richard Nisbett ve arkadaşları (Nisbett, 2004; Norenzayan and Nisbett, 2000) tarafindan yapılan araştırmalarda Batı kültüründe yetişen insanların genellikle çözümleyici düşünme tarzına sahip olduklarını yani çevrelerindeki bağlamı dikkate almadan nesnelerin özelliklerine odaklandıklarını ortaya koymuştur. Doğu Asya düşünme tarzında ise insanlar genellikle bütünselci düşünürler. Yani genel bağlama ve nesneler arasındaki ilişkiye daha çok odaklanırlar. Bu farklılıkların kökeni Doğu ile Batı'nın farklı felsefe geleneklere sahip olmasına dayanır. Doğu düşüncesini her şeyin bağlantılı ve görece olduğunu vurgulayan Konfüçyüs, Taoizim, Budizm gibi felsefi modeller etkiler. Batı düşüncesinin temelinde ise nesneleri bağlamından bağımsız olarak yöneten yasalara odaklanan Aristo ve Platon geleneği bulunur (Aranson vd., 2012: 158).

\subsubsection{Schizmogenesis ya da Pygmalion Etkisi (Beklenti etkisi)}

Schismogenesis dış politikada ya da güvenlik politikalarında bir tür sibernetik çevrim yaratır. Kısaca başkaları hakkındaki önyargılarımız ya da stereotip yaklaşımımıza dayalı olarak geliştirdiğimiz tutumumuz karşımızdakinin de davranışını etkileyerek ortaya tam da beklentilerimiz ya da yargılarımız doğrultusunda bir sonuç çıkmasına neden olur ki bu duruma Pygmalion (beklenti) etkisi veya kendini doğrulayan kehanet adı da verilir. Amerikalı antropolog Gregory Bateson düşman tutumların adeta düşman davranışı teşvik ederek kendi gerekçesini sağlaması şeklinde ilerleyen etki-tepki zincirini ifade etmek üzere bu schismogenesis kavramını kullanmıştır. Türkçe karşılığı bulunmayan kelime kavramsal olarak her ne kadar "ayrılarak doğma" gibi bir anlama geliyorsa da bu tanımlama schismogenesis'i tam olarak ikame edemiyor.

Bateson iki tür schismogenesisten söz eder. Simetrik schismogenesis durumunda tarafların her biri karşısında gördüğü güç belirtilerine tepki gösterir. Rakip ne zaman kuvvet ve kararlılık gösterse daha etkili bir kuvvet ve kararlılık yoluna gidilir. Güvenlik politikalarından biri olan caydırıcılık ve nükleer rekabet simetrik schismogenesis sonucudur. Simetrik schismogenesis çatı̧̧an taraflarda kendini öne çıkarma duygusunu besler ve rasyonel müzakere ve anlaşma ihtimalini ortadan kaldırır. Tamamlayıcı schismogenesis tamamen zıt varsayımlardan doğar ve ikili ilişkilerin kopmasına nede olur. Fakat bu kez taraflardan biri karşı arafın güç ve kararlılığı karşısında gerilerken diğer taraf bu zayıflık belirtisi üzerine kendi kararlılığını daha da artırır. Bu uluslararası alanda tipik olarak merkez-perifer ilişkisinde görülen bir etkileşimdir. Ulusal planda ise tamamlayıcı schismogenesis egemen ve azınlık gruplar arasındaki ilişkide kendini gösterir. Toplumda çoğunluğu oluşturan etnos, bir azınlığın varlığını ancak azınlığın canla başla egemen değerleri kabul ettiğini ve bu egemen kurallara göre yaşamaya istekli olduğunu göstermesi koşuluyla kabul edebilir. Kısaca tamamlayıcı schismogenesiste karşılıklı taraflardan her birinin öteki tarafın ihtiyacı olan bir şeyi karşıladığı bir ilişkidir (Bauman, 2017: 62-64).

Tarih boyunca pek çok ulus birbiri ile etkileşim halinde olmuştur. Bu etkileşim kimi zaman ticaret, kimi zaman savaş biçiminde gerçekleşmiştir. Dolaysıyla bu tecrübeler 1şığı altında toplumların/ulusların birbiri hakkında genel yargıları zihinsel şemaları, stereotipleri, kısa yolları oluşmuştur. Bu zihinsel şemalar genellikle din ya da $1 \mathrm{rk} /$ milliyet etrafinda şekillenmiştir. Bu durum kendisini diş politikada Pan İslamizim, Pan Türkizim, Pan Slavizm, Pan Germenizim, Enosis, Kızılelma, Nippon Miliyetçiliği, Hristiyan-İslam rekabeti ya da çatışması, Haçlı zihniyeti gibi politika ve kavramlarla kendini göstermektedir.

İnsanlar başkalarına davranma biçimiyle farkında olmadan şemaların gerçekleşmesini sağlayabilirler. Karşımızdaki kişilere dair beklentilerimiz bizi belli bir davranışa iterken bu davranış biçimimiz de karşımızdakinin davranışını tetikleyerek ortaya en baştaki 
beklentilerimizi doğrulayan sonuçlar çıarabilir. Kendini doğrulayan kehanet bilinçli kasıttlı bir hareket değil daha çok otomatik düşünmenin bir örneğidir.

\subsubsection{Kültürel Farklılıklar}

Toplumsal ya da Sosyal Biliş üzerine yaptığımız bu açıklamalardan yola çıkarsak insanların çoğunluğunun kontrollü düşünme yerine otomatik ve hızlı düşünmeye daha yatkın oldukları gerçeği bizi toplumun iç ya da diş politika konusunda şemalar ve stereotipler yoluyla tutum sergilediği sonucuna ulaştırır. $\mathrm{Bu}$ düşünme tarzının dış etkenlere, yönlendirmelere açık olması nedeniyle kısa ve uzun vadeli stratejilerle toplumu belli bir davranışı sergilemeye yöneltmek mümkündür. Bunun yanı sıra güvenlik kültürü üzerinde kültürel farklılıkların da önemli etkisi vardır. Bu bağlamda Batı ülkeleri ulusal çıkarları doğrultusunda politikalar geliştirmekte ve bunun için toplumsal destek bulmakta zorlanmazken Doğu ülkeleri ulusal çıkarlarını daha geniş tabanlı ve bölgesel politikalarda aramayı tercih etmişlerdir. Panslavizm, Pantürkizm, Panarabizm, Pan Germenizm gibi politikalar böyle bir yaklaşımın sonucudur. $\mathrm{Bu}$ kültürel farklılıklar felsefi temellere dayandığından düşünce ve yaşam biçiminde yaşanan köklü değişikliklere, inkılaplara, devrimlere ve modernizasyon çabalarına bağlı olarak değişebilir yani toplumlarda zaman zaman kültürel kaymalara rastlamak mümkündür. Örneğin Osmanlı döneminde dış politikada önce İslamcıllk daha sonra ise Türkçülük üzerinden bölgesel ve kolektif politikalar takip edilmek istenirken, Cumhuriyet döneminde Batı felsefesini ve yaşam biçimini benimseyen Atatürk Türkiye'nin dış politikasını öznel ulusal çıkaralar üzerine şekillendirmek istemiş ve felsefi açıdan Türkiye'de bir eksen kaymasına neden olmuştur. Fakat bu değişim tüm yönleriyle kökleşemediğinden Türkiye Doğudan bakıldığında Batılı, Batıdan bakıldığında Doğulu bir toplum gibi görülür.

\subsection{Güvenlik Kültürünün Politik İnşa Boyutu}

Stratejik kültürü üzerine çalışmaları bulunan Snyder (1977: 8) elitlerin özel bir sosyalizasyon sonucu ortaya çıkan bir stratejik kültürü güvenlik ve askeri konulara eklemleyerek ulusal ve uluslararası politikalarını yürüttüklerini ileri sürmüştür. Buradan yola çıkarak güvenlik kültüründe politik inşa sürecinin nasıl işlediği konusuna iyi bir örnek Kopenhag Okulu'nun geliştirdiği güvenlikleştirme (securitisation) teorisidir. Bu teoriye göre siyasal alan içinde çözülebilecek bir problemin tehditler ve çıkarlarla ilişkilendirilerek bir güvenlik sorunu haline gelmesi sürecine güvenlikleştirme denilir (Birdişli 2016a: 101; Emmers, 2007: 112). Güvenlikleştirme sürecinde temel rol oynayan aktörler Snyder'ın ifadesinde de yer aldığ gibi siyasal elitlerdir (Buzan et al., 1998: 23). Bu nedenle ulusal çıkarlar olarak tanımlanan şeylerin gerçekten bütün bir toplumun mu yoksa askeri, siyasal ya da ekonomik seçkinlerin mi çıkarları olduğu konusu tartışıla gelmiştir (Wolfers, 1952: 482).

Teoriye göre bir sorunun güvenlikleştirilmesi o soruna karşı olağan üstü önlemlerin alınmasını makul hale getirir. O nedenle toplumun ikna edilmesi alınacak olan her türlü önlemin ya da yürütülecek olan politikanın işlerliği açısından önem taşır. Bu bağlamda güvenlikleştirme sürecinin bir aşaması tehdit algılama aşaması (threat perception stage) diğeri ise ikna (persuasiveness stage) aşamasıdır (Emmers, 2007: 112). Her iki aşamada hükümetin diğer aktörlere nazaran önemli avantajları vardır, çünkü hükümetin kontrolünde olan kurumlar, basın yayın ve eğitim sistemi güvenlikleştirme sürecine hizmet edebilir.

Güvenlikleştirme sürecinin aktörleri siyasal seçkinler kadar askeriye, sivil toplum ya da hükümet olabilir. Buna karşın korunmak istenen referans objeler: Devlet, gruplar, ulusal bağımsızlık, resmi ideoloji, ekonomi vb. şeylerdir. Neticede referans objelere yönelik tehlikeler birer tehdit olarak tanımlandığında alınacak sert önlemlerde toplum tarafindan hazmedilebilir. Habermas, modern sosyal düzenin sadece ahlaki normlarca değil aynı zamanda giderek artan bir ölçüde politik kurumlar ve yasalarca da şekillendiğini belirtir. 
(Finlayson, 2007: 156) Hatta referans objelerce sağlanan bireysel haklar politik topluluğun ideallerine ve değerlerine bağlıdır ve ondan türerler (Finlayson, 2007:161).

Tehdit algilama ve ikna sürecinde teknoloji, inanç ve tutumlarla iç içe geçmiş güçlü bilişsel kapasite, tarihsel miras ve vizyon, siyaset yapım sürecinin resmi ve gayrı resmi aktörleri önemli roller oynarlar (Snyder, 1977: 94).

\section{Türkiye'de Güvenlik Kültürü ve Türkiye'nin Dış Politikası}

Türkiye'de dış politika üzerine yapılan çalışmalar genellikle jeopolitik ve jeoekonomik eksenlidir. Sosyolojik analizler sınırlı sayıda olduğu gibi dış politikanın temel eksenini ve motivasyonlarını sosyal psikoloji üzerinden çözümleyen çalışmalara hemen hemen rastlamak mümkün değildir. Türkiye bulunduğu coğrafya açısından dünyanın en sorunlu güvenlik bölgelerine komşuluk etmektedir. Bu nedenle gerek bölgesel gerekse ulusal planda güvenlik sorunlarının realist düzlemde ele alınması ve güvenliğin askeri önlemler ile istihbarat faaliyetlerince çerçevelenmiş dar bir alanda ele alınması kanıksanmış durumdadır. Dolayısıyla Türkiye'nin ulusal güvenlik çevriminin hangi kültürel öğelere bağlı olarak biçimlendiği konusunda yapılan çalışmalara da rastlamak mümkün olmamıştır.

Makalenin giriş kısımlarında çizilen teorik çerçeveye bağlı olarak yapılacak bir değerlendirme de ilk göze çarpan şey Türkiye'de iç ve dış politika etkileşiminin 1990'lı yıllara kadar oldukça, konjonktürel ve belli konulara münhasır kalmasıdır. Bunun en temel nedeni Türkiye'nin stratejik kültürel çevrimi öncelikle Türk Dış Politikası'nın temel paradigmalarından biri olan Batılılaşma politikası çerçevesinde biçimlenmiştir. İkinci olarak Türkiye'de hükümet değişimlerine rağmen diş politikadaki öncelikleri askeri ve siyasal elitler tarafindan belirlene gelmiştir. Son olarak da Türkiye'nin uluslararası alanda dost ve düşman paterni de içinde yer aldığı NATO kampının tehdit algıları ve öncelikleri bağlamında belirlenmiştir. Bunun tek istisnası NATO paktında kendisiyle aynı safta yer alan ve NATO'nun bölgesel planlamalarında aynı kategori içine yerleştirilen bir müttefiki olan Yunanistan'ın güvenlik kültüründe düşman olarak algılanmasıdır. Bunun iki nedeni vardır; birincisi Yeni Türkiye Cumhuriyetinin meşruiyet tabanlarından birinin Anadolu'da geniş ölçüde Yunanistan'a karşı yürütülen Türk Kurtuluş Savaşına dayandırılması dolayısıyla, Cumhuriyete yapılan vurgunun doğal olarak Yunanistan'a olan düşmanlığı canlı tutması. İkincisi Yunanistan'la yaşanan adalar, karasuları sınırı, Batı Trakya ve Kıbrıs sorunları gibi kronik sorunlardır. Türkiye'nin bu sorunlarının benzeri bir karşılığı Yunanistan'da da mevcuttur. Bu nedenle Türkiye'nin Yunanistan'la yaşadığı sorunlarda konunun teknik boyutlarının yanı sıra schismogenesis ve pygmalion (beklenti) etkisinden söz etmek mümkündür.

1990 sonrası dönemde ise Varşova Paktı'nın dağılması üzerine Türkiye dış politikasına yön verecek özgün bir stratejik vizyon geliştirme gayreti içine girmiştir. Fakat bu kez toplumda kültürel bölünmüsslüğün neden olduğu düşünsel bir çatışma yaşanmaya başlamıştır. Türkiye'de toplumun bir kesimi kültürel bir taassup gösterirken bir kesimi de yabancı kültür hayranlığı içindedir. Ayrıca eklemlenmiş olduğumuz küresel ekonomik sistemin dışarıdan sağladığı maddi kültür ile moral kültür değerleri arasındaki fark da toplumda çatışmanın bir nedeni olarak güvenlik kültürü içinde varlığını korumaktadır.

1990 sonrası Turgut Özal'la birlikte Türkiye çok boyutlu bir dış politika izlemeyi prensip edinmiş fakat uluslararası koşulların uygunsuzluğu ve kapasite yetersizliği nedeniyle arzu ettiği sonuçlara ulaşamamıştır. 


\subsection{Türkiye'de Toplumsal ya da Sosyal Biliş}

Türkiye'de toplumsal biliş farklı sosyalizasyon süreçleri sonucu ortaya çıkan ikili bir yapıya sahiptir. Toplumun bir kısmı kültürel bir taasub gösterirken diğer bir kesimi ise yabanc1 kültürüne duyulan hayranlık içinde etrafındaki dünyayı algılamaya çalışmaktadır. $\mathrm{Bu}$ nedenle Türkiye'de çerçevesini oryantalizmin(şarkiyatçılık/doğuculuk) ve oksidantiyalizmin (garbiyatçı1ık/batıc1lık) belirlediği şemalar ve stereotipler ile dış dünyayı algılarken oluşan boşlukları doldurmaktadır. Dolayısıyla yüzyıllardır yakın bir ilişki içinde olduğu Batı'yı Kösebalaban (2002) "hem kendisine kavuşulması gereken bir sevgili, hem de kendisinden nefret edilen potansiyel bir düşman" olarak görmekte ve bu paradoks sıklıkla yaşanmaktadır (Kösebalaban, 2002: 130-146).

Bir kesim tarafından Türkiye'nin Oryantalizm ekseninde Hrıstiyanlığa karşı İslam dünyasını temsil eden ve savunan bir ülke olarak görülmesi, güvenlik kültürü bağlamında eksepsiyonalist (kendini ayrıcalıklı görme) bir yaklaşım doğurmaktadır. Karlofça Anlaşmasından günümüze kadar toprak kaybetme korkusu da bir obsesyon (takıntı) olarak dış politik davranışımıza adeta yer etmiştir. Bu kapsamda Uluslararası alana yönelik tehdit algılarımızın gerçeklik düzeyinin, somut bulgulara dayalı olarak test edilmesine büyük gereksinim duyulduğu gözlemlenmiştir. $\mathrm{Bu}$ nedenle güvenlik kültürü konusunda geliştirilecek bir ölçek üzerinden, yapılacak alan araştırmasının Türkiye'nin gelecek vizyonuna önemli katkılar sağlayacağı düşünülmektedir.

\section{Sonuç ve Genel Değerlendirme}

Güvenlik kavramı genellikle realist çerçevede algılanarak ele alınsa da, güvenliğe alternatif yaklaşımlar arasında yer alan birey ve toplum merkezli güvenlik yaklaşımı da giderek önem kazanmaktadır. Özellikle içinde yaşadığımız post-modern dönemde kimlik, aidiyet, farklı1ıklar, toplumsal taleplerin çeşitlenmesi, teknolojik gelişmeler vasıtasıyla siyasete yeni katılım yollarının ortaya çıkmasıyla güvenlik konusunun da çok boyutlu ve multidisipliner ele alınması zorunluluğu ortaya çıkmıştır.

Güvenliğin sosyal boyutlarıyla ilgilenen akademisyenler devlet tarafından tayin edilen ve yürütülen ulusal güvenlik politikaları ile toplumun sahip olduğu kültür arasında yakın bir ilişki ve etkileşim olduğu görüşündedirler. Özellikle Soğuk Savaş yılları döneminde ABD ve Sovyetler Birliği arasındaki nükleer rekabete toplumsal desteğin nasıl sağlandığı konusuna odaklanan uzmanlar, askeri ve siyasal elitlerin dış politika ve uluslararası ilişkiler konusundaki politikalarını özel bir sosyalizasyon sonucu ortaya çıkarttıkları stratejik kültüre eklemleyerek meşruiyet sağladıklarını fark etmişlerdir.

Yönetici elitler tarafından yürütülen sosyalizasyon süreci sonunda devlet politikaları hakkında toplumda oluşan oydaşmaya "Toplumsal ya da Sosyal Bilinç", bu bilince güvenlik ve dış politika konularının eklemlenmesi sonucu ortaya çıkan kültüre de "Stratejik Kültür" denilmektedir.

Stratejik Kültür kavramı uluslararası alanda rekabet halindeki devletlerin davranışlarını açıklamak için oldukça kullanışlı bir kavram olmasına karşın güvenlik konusunda toplumun algı ve tutumunu açıklamak için yetersiz kalmaktadır. Çünkü sonuçta Stratejik Kültür devlet davranışını açıklamak için kullanılan bir kavramdır.

Bu makalede toplumun güvenlik konusundaki alg1 ve tutumunu yani insanlar, nesneler ya da düşünceler ile ilgili değerlendirmelerini tanımlamak üzere Güvenlik Kültürü kavramının kullanımı tercih edilmiş ve sözü edilen değerlendirmelerin sosyal psikoloji yoluyla açıklanmasına çalışılmıştır. 
Araştırmanın bulgularına göre bir toplumun güvenlik kültürünü oluşturan faktörler; Toplumsal ya da Sosyal Biliş, Schizmogenesis veya Pygmalion (Beklenti) Etkisi ve son olarak toplumun kültürel niteliklerinden kaynaklanmaktadır.

Toplumsal ya da Sosyal Bilişin temelinde ise bir konu hakkında hızlı ve otomatik düşünme yetisi anlamına gelen Zihinsel Şemalar ve Stereotipler ile Kontrollü Düşünme yatar. Kontrollü Düşünme, bir konu hakkında araştırmaya ve ayrıntıya girerek karar verme anlamına geldiğinden, insanların çoğu daha düşük gayret gerektiren düşünme biçimi olan hızlı ve otomatik düşünme yani zihinsel şemalar ve stereotipler ile etrafinda olan bitenleri anlamaya ve anlamlandırmaya çalışmaktadır. Fakat hızlı ve otomatik düşünce dış etkenlere oldukça açık bir algılanmadır ve bu algı siyasal iktidar ya da diğer referans objeler tarafından kolaylıkla yönlendirilebilir. Bu durumdaki bir toplumun güvenlik kültürü olguya değil algıya dayalı olacaktır.

Schizmogenesis ya da Pygmalion (Beklenti) Etkisi ise bireylerin ya da toplumların etrafındaki olan bitenle ya da muhataplarıyla ilgili algılarına bağlı olarak geliştirdikleri davranışın muhatabın davranışını da tetikleyerek onları tam da beklentilere uygun bir davranışa sevk etmesi demektir. Bu durum, karşılıklı düşmanlık ya da güvensizliğin güvenlik kültürü açısından bir sibernetik çevrime dönüşmesine neden olacaktır.

Son olarak, yapılan araştırmalar, toplumların kültürel farklılıkları nedeniyle dış dünyayı da farklı biçimde algıladıklarını göstermektedir. Örneğin kültürel olarak Batı toplumları olaylara çözümleyici yaklaşıp, nesnel özellikler üzerine odaklanırken, Doğu toplumları genel bağlama odaklanmakta yani daha bütünselci düşünmektedirler. Bu durum ulusal güvenlik politikalarında doğrudan ulusal çıkarlara odaklanmak açısından Batı toplumlarına bir avantaj sağlarken, Doğu toplumları Panslavizm, Pantürkizm, Panarabizm, Pangermenizm gibi, ya da benzeri ideal/romantik projeler üzerinden daha bütünlükçü politikalara yönelmelerine neden olmaktadır. Özet olarak, zihinsel şemalar ve stereotipler güvenlik kültürünün sosyolojik inşa boyutunun en önemli yapısal faktörleridir.

Güvenlik kültürünün politik inşa boyutunu ise Kopenhag Ekolünün geliştirdiği Güvenlikleştirme (Securitisation) süreci oluşturur. Siyasal alan içinde çözülecek bir sorunun bir tehdit olarak tanımlanarak siyasal alanın dışına çıkartılması ve böylelikle olağanüstü önlemlerin alınmasının mümkün kılınması güvenlikleştirme anlamına gelir. Güvenlikleştirme süreci devlet, siyasal elitler vb. güvenlikleştirme aktörleri tarafından referans objelere yönelik tehditleri algılama, tanımlama ve politika geliştirme sürecidir. Güvenlikleştirme sürecinin en önemli aşamalarını ise Tehdit Algılama (Threat perception) Aşaması ile İkna (persuation) Aşaması oluşturur. Dolayısıyla güvenlik kültürünün gerek sosyal ve gerekse politik boyutunda bir inşa sürecinden ve algı yönetiminden söz etmek mümkündür.

Makalede çizilen bu teorik çerçeve kapsamında Türk Dış Politikasını değerlendirdiğimizde Türk toplumun güvenlik kültürünün olgusal olmaktan daha ziyade algısal etmenlere dayalı olduğu düşünülmektedir. $\mathrm{Bu}$ çalışmada bu tezi doğrulayacak bir alan çalışmasına yer verilmemiştir. Çünkü Güvenlik Kültürü çalışmaları Türkiye'de oldukça sınırlı sayıda gerçekleştirildiğinden bunun yerine ileride yapılacak olan bir alan çalışması için teorik zeminin oluşturulmasına öncelik verilmiştir. Bununla birlikte Türk halkının ortak belleğinde geniş yer tutan Yunanlılara güvensizlik, Araplar konusundaki hayal kırıklığı, Ermeniler konusundaki tereddütler vb. dış dünya değerlendirmeleri, tarihsel olarak yaşanmış olaylara dayanmakla birlikte, toplumda zihinsel şemalara ve stereotiplere neden olmuştur. Bu tarihsel kanaatler doğrultusunda sahip olunan zihinsel şemalar günümüzde Türkiye'nin dış politikası ve güvenlik sorunları konusunda bir Pygmalion (Beklenti) Etkisi yaratmaktadır. 
Türklerin tarihteki başarıları ve parlak bir İmparatorluk geçmişi ise güvenlik kültüründe eksepsiyonalist bir etki yaratmaktadır. Bu nedenle toplumun bir kesiminde tarihin kendini tekrarlayacağı beklentisi bulunmaktadır. Bunda Türklerin diğer Doğu toplumları gibi olaylara bütünselci yaklaşmalarına neden olan kültürel niteliklerinin etkisi olduğu düşünülmektedir. Doğu Batı Kültürü olarak tanımladığımız kültürel farklılıklar bir sabite olmayıp zamanla değiştirilebilir. Türkiye Cumhuriyeti'nin kuruluşunda M. Kemal tarafindan gerçekleştirilen devrimler ve inkılâplar Türkiye'yi kültürel olarak batılı düşünme sistemine evirme çabası olarak değerlendirilmektedir. 


\section{KAYNAKÇA}

ALMOND, G. A. (1956). "Comparative Political Systems". The Journal of Politics, 18 (3), 391-409.

ALMOND, G. A. (1989). "The Intellectual History of the Civic Culture Concept". Civic Culture Revisited, Ed.: Gabriel Almond ve Sidney Verba, First Sage Printing California.

ALMOND, G. A. ve VERBA, S. (1963). The Civic Culture: Political Attitudesand Democracy in Five Nations. Princeton University Press, Princeton.

ARI, T. (2001). Uluslararası İlişkiler ve Dış Politika, (4. Baskı). Alfa Yayınları, İstanbul.

ARONSON, E., WILSON, T. D. ve AKERT, R. M. (2012). Sosyal Psikoloji. Çev.: Okhan Gündüz, Kaknüs Yayınları, İstanbul.

BALDWIN, D. A. (1997). "The Concept of Security". Review of International Studies, 23 (1), 5-26.

BARNARD, F. M. (1969)., "Culture and Political Development: Herder's Suggestive Insights". The American Political Science Review, 63 (2), 379-397.

BATESON, Gregory, (1936), Naven: A Survey of the Problems Suggested by a Composite Picture of Culture of a New Guniea Tribe Drawn from Tree Points of View, Cambridge University Press.

BAUMAN, Z. (2017). Sosyolojik Düşünmek. Ayrıntı Yayınları, İstanbul.

BİLGİN, P. (2003). "Individual and Societal Divisions of Security". International Studies Rewiev, Blackwell Publishing, Oxford.

BİRDİȘLİ, F. (2016a). Teori ve Pratikte Uluslararası Güvenlik, (2. Baskı). Seçkin Yayınları, Ankara.

BİRDIŞLI, F. (2016b). “Güvenlik Kültürü Üzerine Bir Inceleme: Kahramanmaraş Sütçü Imam Üniversitesi Ögrrencilerinin Güvenlik Algisı”. Uluslararası Sosyal Araştırmalar Dergisi, www.sosyalarastirmalar.com , 9 (43), 641-655.

BOOTH, K. (2005). "Strategic Culture: Validity and Validation". Oxford Journal on Good Governance, 2 (1), 25-28.

BRAUCH, H. G. (2008). "Güvenliğin Yeniden Kavramsallaşttrılması: Barış, Güvenlik, Kalkınma ve Çevre Kavramsal Dörtlüsü”. Uluslararası İlişkiler, 5 (18), 1- 47.

BUZAN, B., WAEVER, O. ve De WILDE, J. (1998). Security: A New Framework for Analysis. Lynne Rienner Publishers.

BUZAN, B. (1983). People, States \& Fear: An Agenda for International Security Studies in the Post-Cold War Era. Wheatsheaf Books Ltd., Great Britain.

ÇALIŞ, Ş. H., DAĞI, İ. ve GÖZEN R. (der.), (2001). Türkiye'nin Dış Politika Gündemi; Kimlik, Demokrasi, Güvenlik. Liberte Yayınları, Ankara.

DAĞI, Z. (2007). Uluslararası Politikayı Anlamak: Ulus Devletten Küreselleşmeye. Alfa Yayınları, İstanbul.

DEDEOĞLU, B. (2003). Uluslararası Güvenlik ve Strateji. Derin Yayınlar1, İstanbul. 
Del ROSSO Jr, S. J. (1995). "The Insecure State: Reflections on "The State" and "Security" in a Changing World". Daedalus, 124 (2), 175-207.

DESCH, M. C. (1998). "Culture Clash: Assessing the Importance of Ideas in Security Studies". International Security, 23 (1), 141-170.

EMMERS, R. (2007). "Securitization". Contemporary Security Studies, Ed.: Alan Collins, Oxfort University Press, 109-125.

ERDAĞ, R. (2011). Türkiye’nin Stratejik Kültürü ve Yeni Dış Politikası: Süreçler, Aktörler ve Eylemler. Doktora Tezi, Sakarya Üniversitesi Sosyal Bilimler Enstitüsü, Sakarya.

SARIERTEM, H. (2012), "Kimlik ve Güvenlik İlişkisine Konstrüktivist Bir Yaklaşım: "Kimliğin Güvenliği” ve "Güvenliğin Kimliğì"”. Güvenlik Stratejileri, 8 (16), 177237.

FINNLAYSON, J. G. (2007). Habermas. Çev.: Talat Kılıç, Dost Yayınevi, Ankara.

GRAY, C. S. (1984), “Comperative Strategic Culture”. Parameters, 14 (4), 26-33.

GÜNER, U. A. (2008). Soğuk Savaş Sonrası Dönemde Değişen Güvenlik Algilamaları ve Bir Güvenlik Sorunu Olarak Başarısız Devletler. Yüksek Lisans Tezi, Selçuk Üniversitesi Sosyal Bilimler Enstitüsü, Konya.

HOLTSI, O. R. (1989). "Theories of International Relations". http://www.duke.edu/ pfeaver/holsti.pdf, (13- 07-2017).

HOWARD, M. (1991). “Clausewitz, Man of the Year", New York Times.

JEPPERSON, R., WENDT, A. ve KATZENSTEIN P. (1996). "Norms, Identity and Culture in National Security". The Culture of National Security: Norms and Identity in World Politics, Ed.: Peter J. Katzenstein, Columbia University Press, New York, 3375.

JOHNSON, J. L., KARTCHNER, K. M. ve LARSEN, J. A. (2009). Strategic Culture and Weapons of Mass Destruction: Culturally Based Insights Into Comparative National Security Policymaking. Palgrave Macmillan, New York.

KARDAŞ, T. (2007). "Güvenlik: Kimin Güvenliği ve Nasıl?”. Der.: Zeynep Dağı, Uluslararası Politikayı Anlamak, Alfa Yayınları, İstanbul.

KATZENSTEIN, P. J. (1996). The Culture of National Security: Norms and Identity in World Politics. Colombia University Press, New York.

KELLEY, H. H. (1955). "The Two Function of Reference Group”. Reading in Social Psychology, Ed.: G. E. Swanson, T.M. Newcomb ve E.L. Hartley, NewYork.

KEOHANE, R. O. (1990). "International Liberalism Reconsidered". The Economic Limits to Modern Politics, Ed.: John Dunn, Cambridge University Press, Cambridge.

KIER, E. (1996). "Culture and French Military Doctrine Before World War II", The Culture of National Security: Norms and Identity in World Politics, Ed.: P. J. Katzenstein, Colombia University Press, New York.

KÖSEBALABAN, H. (2002). "Turkey's EU Membership: A Clash of Security Cultures", Middle East Policy, 9 (2), 130-146.

KRAHMANN, E. (2005). New Threats and New Actors in International Security, Palgrave Macmillan, New York. 
KRASNER, S. D. (1983). International Regimes. Ithaca, Cornell UniversityPress.

LANTIS, J. S. (2002). "Strategic Culture and National Security Policy". International Studies Review, 4 (3), 87-113.

LIPP, C. (1996). "Politische Kulturo der das Politischeund Gesellschaftl iche in der Kultur". Geschichteund Gesellschaft, Kulturgeschichte Heute, 16, 78-110.

MANGOLD, P. (1990). National Security and International Relations. Routledge, London.

McSWYEENEY, B. (1999). Identity and Interests: Sociology of International Relations. Cambridge University Press, Port Chester, New York.

MEYER, C. O. (2006). The Quest for a European Strategic Culture: Changing Norms on Security and Defence in the European Union. Palgrave Macmillan, New York.

NISBETT, Richard E. (2004), The geography of Thought: How Asians and Westerners Think Differently and Why?, The Free Press, New York.

NORENZAYAN, Ara and Richard E. Nisbett, (2000), "Culture and Casual Cognition" Current Directions in Psychological Science, 9(4), 132-135.

ONUF, N. (1989). Worlds of Our Making: Rules and Rule in Social Theoryand International Relations. University of South Carolina Press, Columbia.

SHEEHAN, M. (2005). International Security. Lynne Rienner, Boulder.

SNYDER, J. L. (1977). The Soviet Strategic Culture: Implications for Nuclear Options. Rand R-2154-AF, Santa Monica, California.

Sosyal Bilimler Ansiklopedisi (1991). "Siyasi Kültür”. C.3, Risale Yayınları, İstanbul.

SWIDLER, A. (1986). "Culture in Action: Symbols and Strategies". American Sociological Review, 51 (2).

TORUN, A. (2012). Ulusal Güvenlik ve Küreselleşme: Türkiye'nin Ulusal Güvenlik Politikasının Dönüşümünde Küreselleşmenin Rolü. Doktora Tezi, Ankara Üniversitesi Sosyal Bilimler Enstitüsü, Ankara.

WALT, S. M. (1991), "The Renaissance of Security Studies". International Studies Quarterly, 35 (2), 211-239.

WALTZ, K. N. (1979). Theory of International Politics. Addison-Wesley.

WENDT, A. (1999). Social Theory of International Politics. Cambridge University Press, Cambridge.

WOLFERS, A. (1952). "National Security: As an Ambiguous Symbol". Political Science Quarterly, Academy of Political Science Publication, 67 (4), 481-502.

UzZAMAN, R. U. (2009). "Strategic Culture: A Cultural Understanding of War". Comparative Strategy, 28 (1), 68-88. 